\title{
A Simulation Model of Longwall Coal Mining
}

\author{
Victor Okolnishnikov* \\ Institute of Computational Technologies SB RAS, Academician M.A. Lavrentiev avenue, 6, 630090, \\ Novosibirsk, Russia \\ ${ }^{*}$ Corresponding author
}

Keywords: Simulation, Mine, Longwall mining, Productivity, Shearer-loader.

\begin{abstract}
A new simulation model of longwall coal mining is presented. This model intends to research processes by longwall coal mining and to solve a problem of increasing the productivity of a shearer-loader. Using the simulation model the solution of several optimization problems was obtained.
\end{abstract}

\section{Introduction}

Simulation is a powerful tool for solving the problem of increasing the performance of coal mines through the use of new equipment and new technologies. There are many publications about using simulation to solve this problem. In particular there are many publications about using simulation to solve problems connected with longwall coal mining [1,2,3,4,5].

Own simulation system MTSS (Manufacturing and Transportation Simulation System) [6, 7] was applied to solve problems of optimization of longwall technological process for underground coal mines in Kuznetsk Coal Basin (Russia, Western Siberia).

Mathematical and simulation models of longwall technological process in coal mine are considered in this paper. The simulation model was developed with help of MTSS. This model intends to research processes by longwall coal mining and to solve the problem of increasing the productivity of a shearer-loader. Using this simulation model the solution of several optimization problems was obtained.

\section{Case Study}

In mine design, theoretical advance speed $(v)$ and productivity $(A)$ of a shearer-loader in longwall mining is determined from the formulas (1) and (2) [8]:

$$
v=\frac{30 N \eta n_{1} K_{1}}{S D n_{2} K_{o} K}
$$

where:

$N$ is the capacity of shearer drive;

$\eta$ is the efficiency of feed drive gearbox;

$n_{l}$ is the number of picks in a cutting line (assumed subject to the drum design);

$K_{l}$ is the coefficient taking into account a part of capacity of shearer drive to move the shearerloader;

$S$ is the averaged cutting resistance of coal;

$\mathrm{D}$ is the drum diameter;

$n_{2}$ is the number of picks that cut coal simultaneously (for most shearers, this number includes half of all picks on the drum);

$K_{0}$ is the coefficient, taking into account the decreasing of the cutting resistance of coal under the influence of rock pressure;

$K$ is a certain coefficient taking into account the characteristics of cutting angle as well as width, dulling, and shape of picks. 


$$
A=\gamma m v r=\frac{30 m r N \eta n_{1} K_{1}}{S D n_{2} K_{o} K}
$$

where:

$\gamma$ is the coal density;

$m$ is the mineable thickness of coal seam;

$r$ is the shearer cutting width.

The averaged characteristics of the coal seam are used in formulas (1) and (2). More accurate formulas (3) and (4) are proposed in [9]. The averaged characteristics of the coal seam have been replaced by distributed ones. Also the dip angle of coal seam $(\alpha)$ was used.

$v(x, y), A(x, y), \alpha(x, y), S(x, y), m(x, y)$ are functions of the corresponding characteristics of the coal seam in point with $(\mathrm{x}, \mathrm{y})$ coordinates.

$$
v(x, y)=\frac{30 N \eta n_{1} K_{1}}{f P \cos \alpha(x, y) \pm P \sin \alpha(x, y)+S(x, y) m(x, y) n_{2} K_{o}(m(x, y)) K},
$$

where:

$P$ is the shearer weight;

$f$ is the coefficient of sliding friction between shearer and scraper conveyor;

$\alpha$ is the dip angle of coal seam;

"+" and "-" before of the shearer-loader weight correspond the shearer-loader movement up and down the longwall, respectively.

$$
A(x, y)=\frac{30 \gamma(x, y) r N \eta n_{1} K_{1}}{\frac{P}{m(x, y)}(f \cos \alpha(x, y) \pm \sin \alpha(x, y))+S(x, y) n_{2} K_{o}(m(x, y)) K} .
$$

Values of functions $v(x, y), A(x, y), \alpha(x, y), S(x, y), m(x, y)$ are calculated with the method of Inverse Distance Weighting with use of general function (5).

$$
F(x, y)=\left\{\begin{array}{l}
\frac{\sum_{i=1}^{n} d_{i}^{-p} F_{i}}{\sum_{i=1}^{n} d_{i}^{-p}}, \text { if } d_{i} \neq 0 \\
F_{i}, \text { if } d_{i}=0
\end{array},\right.
$$

where:

$n$ is the number of nearest to stoping face wells that are using while calculating;

$F_{i}$ are values of the corresponding characteristics of the coal seam in $i_{\text {th }}$ geological prospecting well;

$d_{i}$ is the length between the mining face with current position $(x, y)$ and the $i_{t h}$ well calculated with (6)

$$
d_{i}=\sqrt{\left(x-x_{i}\right)^{2}+\left(y-y_{i}\right)^{2}},
$$

where $\left(x_{i}, y_{i}\right)$ is the coordinates of the $i_{t h}$ well.

The coal cutting resistance $S$ affects the motion rate of shearer-loader to a greater extent than other characteristics of the coal seam.

The coal cutting resistance $S$ is calculated by data obtained when drilling the geological prospecting well using (7).

$$
S_{i}=\frac{m_{r} f_{r}+m_{c} f_{c}}{m_{r}+m_{c}},
$$


where:

$m_{r}, m_{c}$ are the rock mass and the coal mass respectively;

$f_{r}, f_{c}$ are the interbed rock hardness and the coal hardness respectively.

\section{Simulation Results}

An integrated model of a longwall coal mining was implemented in the frames of simulation system MTSS. This model involves the following interacting parts: the shearer-loader model itself, the coal seam model, and the model of a self-moving roof support. We assure that all parameters of the models of mine equipment correlate with the parameters of the actual mine equipment. It operates at one of the coal mines in Kuznetsk Coal Basin.

The evaluation of productivity of a shearer-loader which depends on different factors such as specifications of the shearer-loader and geophysical conditions of the coal seam was set as the main goal of the simulation of longwall coal mining.

In Fig. 1 we present the main window of the longwall coal mining model which was carried out with simulation system MTSS. There the coal seam with one geological prospecting well (a red circle) is painted over. The areas showing reduced resistance are painted over in a lighter shade.

There is a possibility to set interactively in the parameters window the equipment parameters as well as operation modes. In order either to start the shearer-loader or to stop it we enter the control buttons in the main window. The state of the coal seam (the coal cutting resistance) is the main factor which influence on the shearer-loader productivity as it restricts the shearer advance speed. The subject of the research is to simulate in details both one-way operating and shuttle operating of the shearer-loader taking into account roof supports movement which depend on geophysical state of coal seam.

There was performed a series of experiments along with the developed longwall mining simulation model. We calculated the average productivity of the shearer-loader both for one-way and for shuttle operating, in dependence of the length of the longwall face. The experiments were carried out under the equal conditions of the passage of the shearer-loader for a certain depth into the coal seam.

Fig. 2 shows the results in the form of graphs.

We can make the following conclusions:

- The shuttle operating of coal mining is more productive in comparison with the one-way operating;

- The increase of the length of the longwall face, starting from a certain value, does not affect significantly the increase in the productivity of the shearer-loader.

With the developed longwall mining simulation model a dependence of the shearer-loader advance speed and productivity of the shearer-loader on the shearer cutting width was calculated. This dependence for the shearer-loader SL-500/1 and coal seam $3 \mathrm{~m}$ thick is presented in Fig. 3.

SL-500/1 shearer-loader has the following specifications: mineable coal thickness range is $2-5 \mathrm{~m}$; allowable dip angle of coal is $35^{\circ}$; total capacity of motors is $948 \mathrm{~kW}$; cutting drive capacity is 700 $\mathrm{kW}$; feed drive capacity is $108 \mathrm{~kW}$; drum diameter is $1.6 \mathrm{~m}$.

The obtained results allow us to conclude that the productivity of shearer-loader has a point of maximum with respect to the shearer cutting width. 


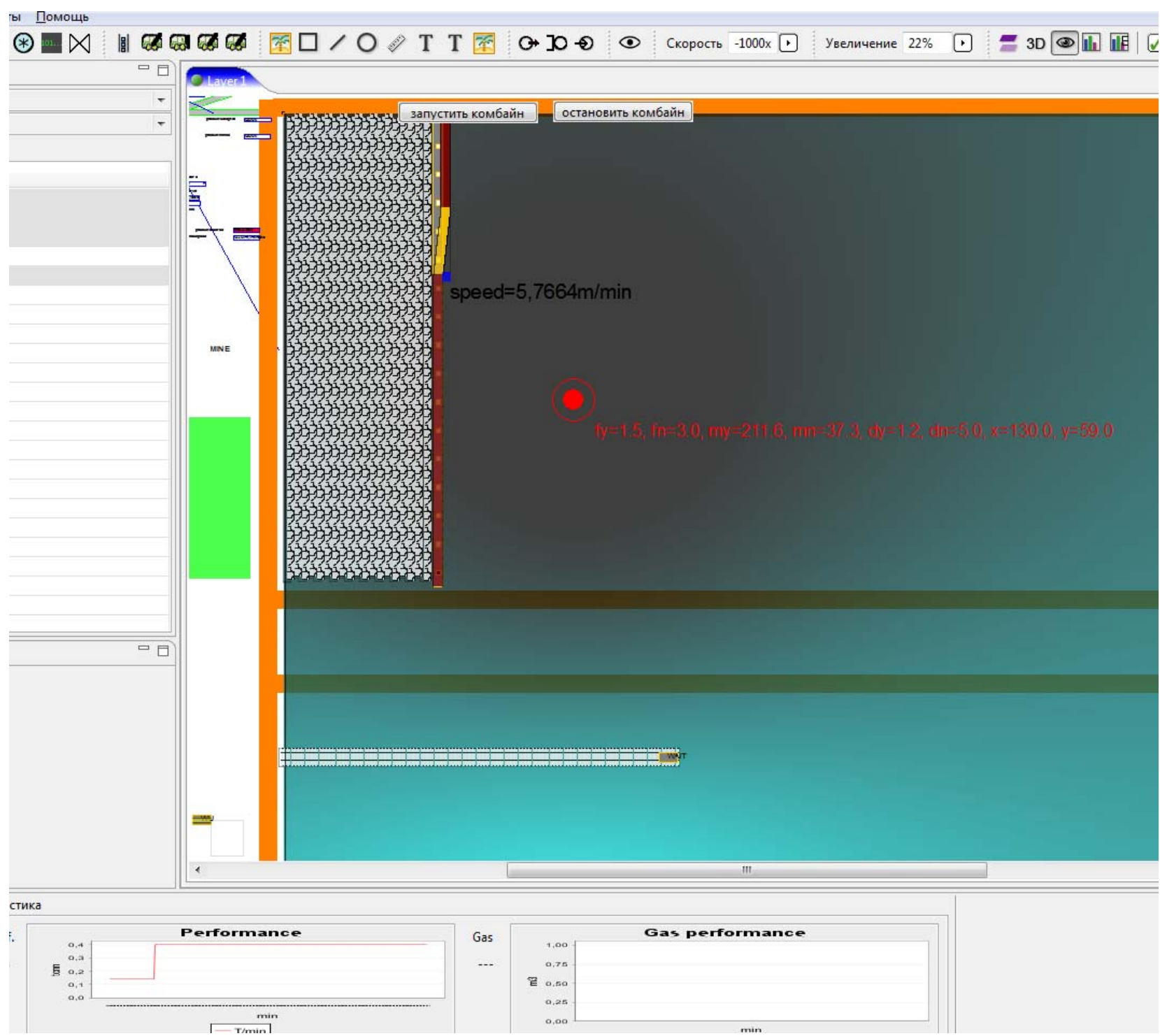

Figure 1. The main window of the longwall coal mining model

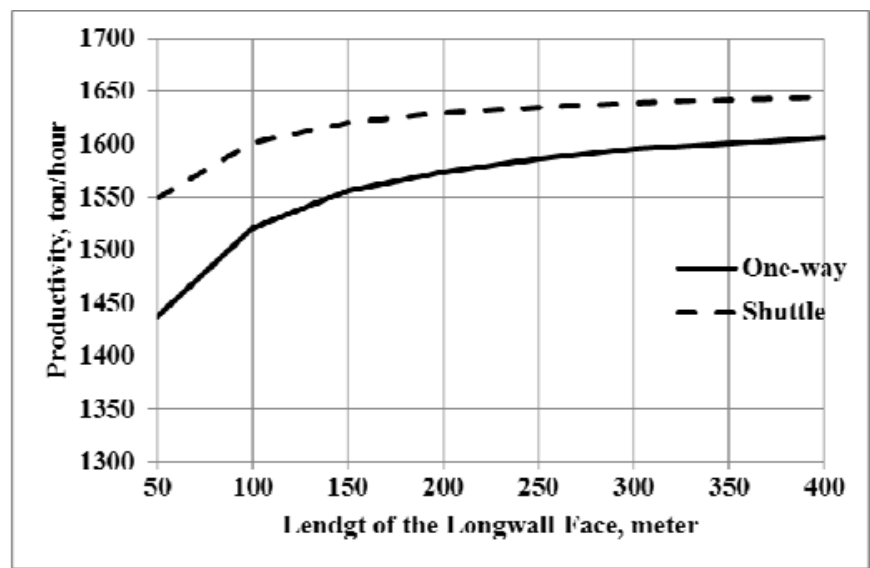

Figure 2. Shearer-loader performance depending on longwall face length 


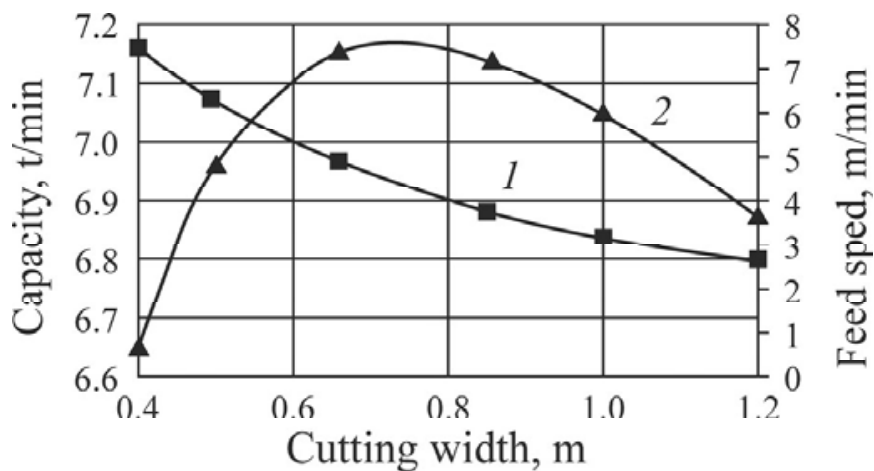

Figure 3. The dependence of the shearer advance speed (Line 1) and productivity (Line 2) of the shearer-loader on the shearer cutting width for the shearer-loader SL-500/1

\section{References}

[1] D. Cai, E. Baafi and I. Porter, Modelling a longwall production system using flexsim 3D simulation software, in: R. Singhal, E. Topal, K. Fytas, M. Yellishetty \& A. Mehrotra (Eds.), Mine planning and equipment selection, Irvine, California, USA, 2012, pp. 107-114.

[2] T.N. Michalakopoulos, C.P. Roumpos, M.J. Galetakis and G.N. Panagiotou G.N., Discrete-Event Simulation of Continuous Mining Systems in Multi-layer Lignite Deposits, Lecture Notes in Production Engineering, Proceedings of the 12th International Symposium Continuous Surface Mining, (2015) 225-239.

[3] P. Gospodarczyk, Modeling and Simulation of Coal Loading by Cutting Drum in Flat Seams, Archives of Mining Sciences 61(2), (2016) 385-379.

[4] Jinxia Liu, Chao Ma, Qingliang Zeng and Kuidong Gao, Discrete Element Simulation of Conical Pick's Coal Cutting Process under Different Cutting Parameters, Shock and Vibration, 2018, Information on https://doi.org/10.1155/2018/7975141.

[5] M. Kęsek, A. Adamczyk and M. Klaś, Computer Simulation of the Operation of a Longwall Complex Using the "Process Flow" Concept of FlexSim Software, in: A. Burduk, E. Chlebus, T. Nowakowski and A. Tubis (Eds.), Advances in Intelligent Systems and Computing, 835, Springer, Cham, 2019.

[6] V.V. Okolnishnikov, S.V. Rudometov, A System for Computer Simulation of Technological Processes, St. Petersburg State Polytechnic University Journal, Computer Science, Telecommunications and Control Systems 1 (2014), 62-68.

[7] V.V. Okolnishnikov, S.V. Rudometov and S.S. Zhuravlev, Simulating the Various Subsystems of a Coal Mine, Engineering, Technology \& Applied Science Research 6(3), (2014) 993-999.

[8] A.A. Ordin, A.A. Metel'kov, Optimization of the fully-mechanized stoping face length and efficiency in a coal mine, Journal of Mining Science 49(2), (2013), 254-264.

[9] A.A. Ordin, V.V. Okolnishnikov, S.V. Rudometov and A.A. Metel'kov, Otsenka proizvoditel'nosti ochistnogo kombinata pri izmenyayushchikhsya gorno-tekhnicheskikh i geomekhanicheskikh kharakteristikakh ugol'nogo plasta (Evaluation of the performance of a shearer-loader depending on changing characteristics of the coal seam), FTPRPI 1, Institute of Mining. Novosibirsk, (2019), 64-73. (In Russian). 